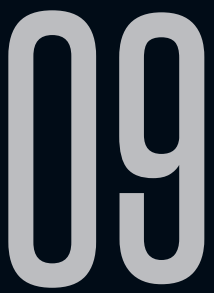

\title{
ROBERT LOUIS STEVENSON E O INSÓLITO JOGO DE ESPELHOS EM MARKHEIM (1884)
}

Renato Barros de Castro (UFRGS)

Recebido em 01 mar 2020. Renato Barros de Castro é Doutorando do Programa Aprovado em 05 jul 2020. de Pós-Graduação em Letras da Universidade Federal do Rio Grande do Sul (UFRGS). É servidor público da Universidade Federal do Ceará (UFC), onde concluiu Mestrado em Letras (Literatura Comparada). É graduado em Comunicação Social (Jornalismo) e tem experiência na área de Letras e Comunicação. Autor do livro de contos de literatura fantástica $O$ mistério de Frida Zeiden, obra finalista do Prêmio SESC de Literatura de 2016, e dos livros de crônicas Viagem a um Brasil insólito (2015), vencedor do Prêmio de Incentivo à Publicação e Divulgação de Obra Inédita da Secretaria de Cultura do Estado do Ceará (SECULT), e Geografia afetiva (2011), vencedor do Prêmio Milton Dias (2011), dentre outros. Também é autor de artigos em periódicos e obras bilíngues como Plac Bohaterów Getta, publicada na Polônia.

Lattes: http://lattes.cnpq.br/8678460241083520

Email: renatobdecastro@gmail.com

ORCID iD: https://orcid.org/0000-0002-9458-3360

Resumo: Este trabalho aborda um dos temas mais caros à literatura fantástica, a saber, o tema da duplicidade e da multiplicidade do "eu", construído

1 Título em inglês: "Robert Louis Stevenson and the uncommon game of mirrors in Markheim (1884)". 
em uma narrativa de crime que privilegia uma série de eventos insólitos. A partir de uma análise sobre as discussões acerca do gênero fantástico e do seu surgimento, tendo por fundamentação teórica autores como Tzvetan Todorov e David Roas, o artigo pretende analisar o conto "Markheim" (1884), de Robert Louis Stevenson (1850-94), sob a perspectiva da construção da alteridade na narrativa, sem deixar de considerar os demais elementos que dialogam com textos de Edgar Allan Poe, um dos predecessores canônicos no gênero. Em "Markheim", como em nenhuma outra narrativa de Stevenson (mesmo em O estranho caso de Dr. Jekyll e Mr. Hyde), pode-se apreciar com tanta clareza a capacidade construtiva do autor e a forma como orquestra o uso dos elementos emblemáticos do fantástico e do insólito, conduzindo o leitor gradativamente ao estado de hesitação de que fala Todorov. Tudo isso não apenas por conta da meticulosa escolha das palavras, mas também graças a uma habilidade ímpar em evocar imagens, criar atmosferas e - principalmente - levar o tema da duplicidade ao ponto de proporcionar, ao leitor, uma reflexão aprofundada sobre a consciência humana e aos estranhos "eus" que carrega em si mesmo. Estudando o modo como se dá a construção dos elementos emblemáticos do fantástico na narrativa de crime Markheim - bem como os elementos de desestabilização da realidade -, este estudo espera trazer à tona um dos esteios da obra de Stevenson, revelador das angústias de toda uma geração de escritores.

Palavras-chave: Stenvenson; Literatura Fantástica; Narrativa de Crime.

Abstract:This work approaches one of the most important themes of fantastic literature: the theme of duplicity and the multiplicity of the "self", built on a crime narrative that privileges a serie of uncommon events. From an analysis of the discussions about 
the fantastic genre and its emergence, based on theoretical authors such as Tzvetan Todorov and David Roas, the article intends to analyze the tale Markheim (1884), by Robert Louis Stevenson (185094), from the perspective of the construction of alterity in the narrative, also considering other elements that dialogue with texts by Edgar Allan Poe, one of the canonical predecessors of the genre. In Markheim, as in no other story by Stevenson (even The strange case of Dr. Jekyll and Mr. Hyde), it's clearly possible appreciate the author's constructive capacity and the way wich he orchestrates the use of the symbolic elements of the fantastic and the uncommon, gradually leading the reader to the state of hesitation told by Todorov. All this not only because of the meticulous choice of words, but also thanks to an unique ability to evoke images, to create atmospheres and - above all - to bring the theme of duplicity to the point of providing the reader with an in-depth reflection on human consciousness and the stranges "selfs" that they may carry in themselves. Studying the construction of the emblematic elements of the fantastic in the crime narrative Markheim - as well as the destabilizing elements of reality - this research expects to bring to the surface one of Stevenson's works bases, revealing the anxieties of an entire generation of writers.

Keywords: Stevenson; Fantastic Literature; Crime Narrative.

\section{O DUPLO E A LITERATURA FANTÁSTICA}

O tema do duplo é um dos mais recorrentes na literatura, talvez exatamente por apontar para um dos fulcros que a própria atividade literária impõe aos autores: colocar-se no lugar do outro. Afinal, escrever é tornar-se outro, imaginar outras vidas e espaços mentais fora de si mesmo. Projetar-se. 
Poucos gêneros ou subgêneros (delimitar tal campo é incorrer em polêmica) souberam explorar tão bem esta temática como o conto fantástico, exatamente por possibilitar uma abordagem e análise mais ampliadas da realidade, em suas profundas camadas, e, desse modo, revelar outros níveis da consciência e do mundo, a partir da multiplicidade de pontos de vista e da subjetividade dos autores: afinal, a pluralidade da realidade coincide com a pluralidade da persona.

Segundo Todorov, o fantástico é uma categoria definida pela percepção difusa que o leitor tem dos fatos narrados, compartilhados seja com o narrador seja com determinados personagens: "O fantástico é a hesitação experimentada por um ser que só conhece as leis naturais, face a um acontecimento aparentemente sobrenatural" (1992, p.31).

Para David Roas, entretanto, a concepção de Todorov é bastante restritiva, acabando por deixar de fora muitas narrativas. Para Roas, a vacilação não pode ser aceita como traço delimitador do gênero fantástico, uma vez que não abrange todas as narrativas assim classificadas:

Minha definição inclui tanto as narrativas em que a evidência do fantástico não está sujeita a discussão, quanto aquelas em que a ambiguidade é insolúvel, já que todas postulam uma mesma ideia: a irrupção do sobrenatural no mundo real e, sobretudo, a impossibilidade de explicá-lo de forma razoável. (2014, p.43)

O autor também não deixa de fora outro ponto essencial da literatura fantástica: a participação do leitor - fundamental para a própria existência do fantástico na literatura -, uma vez que é 
necessário levar em conta o contato entre o contexto da história narrada e a realidade propriamente dita. Desse modo, o horizonte cultural do leitor (e o que ele entende por real) é um fator decisivo para esse tipo de narrativa:

Baseada, portanto, na confrontação do sobrenatural e do real dentro de um mundo ordenado e estável como pretende ser o nosso, a narrativa fantástica provoca - e, portanto, reflete a incerteza na percepção da realidade e do próprio eu; a existência do impossível, de uma realidade diferente da nossa, leva, por um lado, a duvidar desta última e causa, por outro, em direta relação com isso, a dúvida sobre nossa própria existência, o irreal passa a ser percebido como real, e o real, como possível irrealidade. [...] Em última instância, a literatura fantástica manifesta a validade relativa do conhecimento racional, iluminando uma zona do humano onde a razão está condenada a fracassar. (ROAS, 2014, p.32)

Ressaltada a importância do contexto cultural, faz-se necessária a localização temporal do surgimento do gênero. Embora para muitos o fantástico esteja presente na literatura de todas as épocas, tendo existido desde sempre, Roas aponta seu início especificamente no século XVIII, o que se explica pelo fato de, até o advento dessa época, o sobrenatural integrar o horizonte de perspectivas do leitor: com o lluminismo, findouse a crença nos fenômenos sobrenaturais como algo inerente ao cotidiano humano.

Somente com o Romantismo, porém, o fantástico atingiria plena maturidade, uma vez que foi nesse período que os homens passaram a dar um novo tratamento ao sobrenatural, levando 
em conta, agora, que, mesmo com todos os avanços da ciência, boa parte do mundo e do comportamento humano continuava sem explicação: o mundo passou a ser visto como algo muito mais misterioso do que julgava o homem sistemático e racional do lluminismo.

François Furet assim expressa essa nova visão de mundo a partir da figura do intelectual:

O intelectual romântico nunca se entrega duradouramente ao otimismo histórico. Porque o atormenta uma ambivalência mais essencial do que as suas simpatias políticas. Ele é o homem do eu, destinado à destruição do eu. Tem o gosto do eu, deleita-se no gozo do seu eu, segundo o exemplo de Rousseau. E, contudo, a ideia de morte nunca o abandona, matriz de uma obsessão da fatalidade. $(1999$, p.15)

Dentro desse contexto, é exatamente com a ascensão do fantástico no Romantismo que o tema do duplo atingiria igualmente seu ápice, como se dele estivesse indissociado, e, ao mesmo tempo, fosse uma de suas facetas mais representativas: afinal, o mergulho romântico no "eu" e na descoberta de si mesmo acabou por implicar na revelação de uma multiplicidade de personas em cada indivíduo, e poucos autores trouxeram tal verdade à tona com a força de Edgar Allan Poe (1809-49), um dos mais representativos de sua época e cuja influência iria se estender a muitos escritores, reverberando em Robert Louis Stevenson (1850-94).

O conto William Wilson (1839), de Poe, é um texto emblemático desse conflito da pluralidade da individualidade, 
o qual é ilustrado por meio do uso da imagem de um espelho, símbolo icônico da duplicidade:

Um vasto espelho - em minha perturbação pareceume assim, a princípio - erguia-se no ponto onde antes nada vira; e, enquanto me dirigia tomado de horror, para esse espelho, minha própria imagem, mas com o rosto pálido e manchado de sangue, adiantou-se ao meu encontro, com um passo fraco e vacilante.

Foi o que pareceu, repito, mas não era. Era meu adversário, Wilson, que diante de mim se contorcia em agonia. Sua máscara e capa jaziam sobre o soalho, no ponto onde ele lançara. Não havia um fio de sua roupa - nem uma linha em toda sua figura tão característica e tão singular - que não fossem meus: era o absoluto na identidade!

Era Wilson, mas Wilson sem mais sussurrar agora as palavras, tanto que teria sido possível acreditar que eu próprio falava, quando ele me disse:

- Venceste e eu me rendo. Mas, de agora em diante, também estás morto... morto para o Mundo, para o Céu e para a Esperança! Em mim tu existias... e vê em minha morte, vê por esta imagem, que é a tua, como assassinaste absolutamente a ti mesmo (POE, 1975, p.107)

Poe também iria abordar essa mesma temática, embora de forma mais sutil, em $O$ homem das multidões (1840), no qual o narrador persegue um homem anônimo pelas ruas de Londres, ao sabor do acaso, e de quem nada consegue descobrir: "De vez em quando, ai!, a consciência do homem suporta uma carga tão pesada de horror que só pode ser descarregada na sepultura. E dessa forma a essência de todos os crimes fica irrevelada" (POE, 1981, p.392). 
Sendo o desconhecido em questão uma espécie de protótipo da humanidade - um pedestre qualquer escolhido como objeto de observação -, vemos a reverberação da ideia do espelho como duplicação do personagem em um ponto determinado da trama, no qual narrador e personagem observado se cruzam, na rua, e se encaram:

E lá, ainda, em meio à confusão que aumentava a todo instante, continuei minha perseguição do desconhecido. Mas, como sempre, ele andava pra lá e pra cá, e durante o dia não saiu do turbilhão daquela rua. E, como as sombras da segunda noite caíssem, senti-me fatigado de morte e, parando bem defronte do vagabundo, encarei-o fixamente. Ele não me deu atenção, mas continuou seu solene passeio, enquanto eu, cessado de acompanhá-lo, permanecia absorto em contemplação. (POE, 1981, p.400)

Recorrente em inúmeros textos literários que, de modo direto ou indireto, tratam do tema do duplo, o espelho como símbolo da duplicidade tem sua origem no mito grego de Narciso, como aponta Davide Falcione (2005): "Narciso [é] símbolo do duplo, do desdobramento e da duplicidade" (FALCINONE, 2005, p. 141), exatamente por expressar de modo muito claro a questão da possibilidade de o indivíduo observar-se, de tomar consciência de sua própria imagem exterior. $E$, também, de tomar consciência da falta de uma unicidade interna, a qual corresponderia a uma representação social do indivíduo, isto é, a imagem que, com base em sua constituição cultural, o indivíduo é forçado a apresentar aos outros como coerente, embora, em sua realidade mais íntima, ele saiba que tudo não passa de um jogo o qual é 
obrigado a jogar, não raras vezes contra sua própria vontade ou contra suas próprias forças, a fim de ser socialmente aceito e poder viver em comunidade.

Afinal, a identidade social nem sempre corresponde à imagem que o indivíduo tem de si mesmo, bem como não consegue encerrar todas as facetas de uma mesma pessoa, a qual, conforme os estudos de psicanálise já deixaram claro - o que foi muitas vezes antecipado na própria esfera do ficcional -, a unicidade do "eu" não passa de uma grande e, até surpreendente, ilusão.

\section{O DUPLO EM STEVENSON}

A ideia da ilusão da unicidade do "eu" surge exatamente da oposição primordial entre indivíduo e sociedade, entre o que uma pessoa é e o que esperam que ela seja; entre a verdade subjetiva e as necessidades impostas pela vida em comunidade. Em suma: entre a forma como uma pessoa enxerga a si mesma e a forma como os outros a enxergam, bem como o choque resultante entre ambas.

Aqui, mais uma vez, nos vemos nos domínios de um conflito abordado por Stevenson em sua narrativa mais conhecida: 0 estranho caso de Dr. Jekyll e Mr. Hyde (1886), talvez a mais famosa história já escrita sobre a cisão da personalidade e os conflitos disso resultantes, e que também, não à toa, utiliza-se da carga simbólica do objeto espelho, a partir do qual o protagonista se vê face a face com o seu duplo, Mr. Hyde:

Por mais que o bem brilhasse no semblante de um, o mal estava ampla e nitidamente escrito na face do outro. Além disso, o mal (que ainda 
acredito ser a parte letal de um homem) deixara naquele corpo uma marca de deformidade e deterioração. Entretanto, quando olhei para aquela horrível figura no espelho, estava consciente de não sentir repugnância nenhuma, e sim o impulso de lhe dar as boas-vindas. Aquele também era eu. Parecia natural e humano. A meus olhos, exibia a imagem de um espírito mais vivaz. Parecia mais exato e inteiro do que o imperfeito e dividido semblante que eu costumava chamar de meu. [...] Todos os seres humanos, tal como os conhecemos, são uma mistura do bem e do mal, e apenas Edward Hyde, no gênero humano, era puro mal (STEVENSON, 2015, p.194)

Vladimir Nabokov, entretanto, chama a atenção para um aspecto importante que passa despercebido para muitos leitores dessa obra: "Jekyll realmente não se transforma em Hyde, e sim projeta um concentrado de maldade pura que se torna Hyde. [...] $\mathrm{Na}$ verdade, existem três personalidades: Jekyll, Hyde e uma terceira, o resíduo de Jekyll quando Hyde assume o controle" (NABOKOV, 2015, p.396). Esse resíduo, por sua vez, diz respeito exatamente ao fato de Hyde desejar voltar a ser Jekyll.

Jekyll não é o bem puro, assim como Hyde (malgrado a afirmação em contrário de Jekyll) não é o mal puro, pois, tal como certas partes do inaceitável Hyde estão presentes no aceitável Jekyll, igualmente sobre Hyde paira um halo de Jekyll, horripilado com as iniquidades de sua metade maligna (NABOKOV, 2015, p.398)

Assim como em O estranho caso de Dr. Jekyll e Mr. Hyde sobressai o tema da duplicidade (ou multiplicidade, como prefere Nabokov), percebemos uma recorrência a esse tema nas narrativas 
de Stevenson, recorrência que chega mesmo a se revelar como um dos esteios da sua ficção, reverberando em personagens e enredos os mais variados, e de modo também exemplar em $O$ clube do suicídio (1878), no qual o ato de assumir outras identidades por parte dos protagonistas, o coronel Geraldine e o príncipe Florizel da Boêmia, é exatamente o que irá desencadear a trama:

Vasta experiência e conhecimento variado sobre as coisas da vida lhe conferiam uma singular aptidão para os disfarces; era capaz de adaptar não apenas o rosto e a postura, mas também a voz, e quase seus pensamentos, àqueles de qualquer condição social, personalidade ou procedência; e dessa forma desviava do príncipe todas as atenções, e por vezes até conseguia acolhida para a dupla em estranhos círculos. As autoridades civis nunca ficavam a par dessas aventuras; a imperturbável coragem de um associada à rápida capacidade inventiva e à cavalheiresca devoção do outro os conduziram por dezenas de situações arriscadas, e com o passar do tempo isso fez aumentar a mútua confiança entre os dois. [...]

O coronel Geraldine estava vestido e maquiado para se fazer passar por um jornalista em dificuldades financeiras, enquanto o príncipe, como de costume, havia travestido sua aparência acrescentando falsas costeletas e duas grandes sobrancelhas adesivas. Isso the emprestava o ar rude e castigado pelas intempéries que, para alguém tão urbano quanto ele, constituía o mais insondável disfarce (STEVENSON, 2015, p.10)

Embora a escolha deliberada por assumir disfarces não implique conflitos de consciência como os presentes em $O$ estranho caso de Dr. Jekyll e Mr. Hyde ou em Markheim (como 
se verá adiante), é, porém, essa mesma atitude que irá levar os personagens Geraldine e Florizel ao encontro de aventuras insuspeitas e a consequências quase desastrosas.

Em suma, se os protagonistas de $O$ clube do suicídio não se veem numa luta interior entre o que são e o que a sociedade exige deles (ou entre o bem e o mal em si mesmos), eles precisam, todavia, de disfarces para não serem reconhecidos e assim poder vivenciar experiências além do que seus papéis sociais Ihes permitiriam. - É de uma forma consciente que põem em marcha o desdobramento da personalidade, fugindo do tédio da sociedade vitoriana e do papel desempenhado no dia a dia.

Apesar dessa nuance, ainda assim, continua-se no domínio do duplo: conforme já referido, o esteio da ficção de Stevenson.

\section{O DUPLO EM MARKHEIM}

Uma vez apresentadas as variações de um mesmo tema em outras obras do autor, bem como o predecessor (Poe) com o qual elas mais dialogam, o conto Markheim (1884) é um texto do gênero fantástico no qual o tema do duplo é tratado com o máximo destaque dentro das narrativas curtas de Stevenson, mesmo permanecendo à sombra de O estranho caso de Dr. Jekyll e Mr. Hyde e continuando, ainda hoje, desconhecida por boa parte do público.

Em Markheim, como em nenhuma outra narrativa curta de Stevenson, pode-se apreciar com tanta clareza a capacidade construtiva do autor e a forma como ele orquestra o uso dos elementos emblemáticos do fantástico, conduzindo o leitor gradativamente ao estado de hesitação de que fala Todorov, 
não apenas por conta da meticulosa escolha das palavras, mas também graças a uma habilidade ímpar em evocar imagens, criar atmosferas e - principalmente - levar o tema da duplicidade ao ponto de proporcionar, ao leitor, uma reflexão aprofundada sobre a consciência humana e aos estranhos "eus" que carrega em si mesmo.

Assim como ocorre em $O$ clube do suicídio e $O$ estranho caso de Dr. Jekyll e Mr. Hyde, a trama de Markheim também se utiliza do objeto mais tradicionalmente usado pelos autores que pretendem tratar do tema da duplicidade - como já explicado, o espelho, desta vez chamado também de "consciência portátil" (STEVENSON, 2015, p. 218), expressão reveladora do que o autor pretenderá abordar na história.

Na abertura da narrativa, o protagonista - de nome Markheim - dirige-se a um antiquário, sob o pretexto de comprar um presente para uma dama a qual pretendia desposar. Desse modo, ele recebe a oferta de um espelho do século XV como o presente ideal, ao que recusa peremptoriamente: "O senhor me pergunta por que não? [...] Ora, olhe aqui - olhe bem dentro dele -, olhe para si mesmo! Gosta de olhar para isso? Não! Nem eu... nem homem nenhum" (STEVENSON, 2015, p.217).

O uso do espelho, já no início da trama, não é mesmo por acaso; é exatamente a partir dele que Stevenson conduzirá o leitor para um outro tipo de duplicação, isto é, o encontro do personagem com o seu duplo, a partir do qual o personagem irá ficar cara a cara com a sua outra parte e encarar as consequências de seus atos. 
Um dos pontos mais relevantes da trama de Markheim é, a propósito, o momento em que o antiquário inclina-se para devolver o espelho ao local de onde o tinha retirado, ocasião em que o protagonista vai perpetrar o ato que, na verdade, foi o motivo de ter se dirigido até ali, a fim de desferir o golpe mortal:

A longa e pontiaguda adaga cintilou e caiu.

O antiquário lutou como uma galinha, bateu

a têmpora na prateleira e depois tombou amontoado no chão. Naquela loja, o tempo era contado com um coro de pequenas vozes, algumas impotentes e vagarosas como convinha à sua idade avançada; outras, tagarelas e apressadas. Todas anunciavam os segundos num intrincado coro de tique-taques. Naquele momento, o som dos passos de um rapaz correndo pesadamente na calçada se sobrepôs a essas pequenas vozes, e de repente devolveu a Markheim a consciência do que se passava à sua volta. (STEVENSON, 2015, p.219-220)

Na sequência dessa mesma cena, Stevenson põe em marcha sua estratégia de fisgar o leitor, não só capturando-o ao levá-lo diretamente ao âmago do cenário descrito com a ajuda de elaboradas referências auditivas e visuais, mas também dando início a uma sutil criação de atmosfera ao gosto do fantástico: "Os rostos nos retratos e os deuses de porcelana deformavam-se em ondulações qual imagens na água. A porta interna se mantinha entreaberta e espreitava aquele cerco de sombras com seu longo feixe luminoso a intrometer-se como um dedo acusador" (STEVENSON, 2015, p.220).

Esta deformação dos objetos e das sombras, a propósito, constitui um exemplo típico da construção da atmosfera no conto fantástico em geral, revelando o início de uma ruptura 
na ordem das leis naturais que o leitor conhece e com a qual convive em seu dia a dia:

A literatura fantástica é aquela que oferece uma temática tendente a pôr em dúvida nossa percepção do real. Portanto, para que a ruptura [...] se produza é necessário que o texto apresente um mundo o mais real possível que sirva de termo de comparação com o fenômeno sobrenatural, isto é, que torne evidente o choque que supõe a irrupção de tal fenômeno em uma realidade cotidiana. O realismo se converte assim em uma necessidade estrutural de todo texto fantástico. (ROAS, 2014, p.51)

Ressalta-se, ainda, que a alteração da percepção do ambiente pelo protagonista, em Markheim, é fundamental para a construção da cena, potencializada pela concomitância dos sons a ecoar ao redor do personagem que vinha de cometer um crime, reforçando a atmosfera de pesadelo. Como em uma caixa de ressonância, a loja de antiguidades amplifica os mínimos ruídos do ambiente, reforçando o tom de alucinação a envolver o personagem e, ao mesmo tempo, a tensão gradual com que se depara o leitor:

O tilintar dos cálices altos de cristal da Boêmia era forte como de um sino, e, alarmado pela grandiosidade de todo aquele tique-taque, ele se sentiu tentado a parar os relógios. E de novo, numa transição abrupta de pavor, o próprio silêncio do lugar pareceu uma fonte de perigo e algo capaz de intrigar e deter algum transeunte. (STEVENSON, 2015, p.222)

A importância dada a toda essa amplificação sonora, a propósito, também remete indiretamente a outro texto de Poe, 
a saber, O coração denunciador (1843), onde os sons têm uma relevância capital, servindo até mesmo para desencadear o clímax da trama, assim como em Markheim, onde eles já denotam uma espécie de punição antecipada: "Se ao menos fosse surdo, [...] quanta tranquilidade teria na alma!" (STEVENSON, 2015, p. 227).

Ressalta-se, ainda, que a percepção alterada do personagem Markheim lança-o a uma espécie de estágio paranoico onde tanto ele se sente denunciado por sons que, em outras circunstâncias, passariam despercebidos (os sons são responsáveis por fazer surgir tal paranoia), como também isso o leva a se sentir observado: "Entretanto, ali naquela claridade incerta, não era verdade que se encontrava uma sombra tremulante?" (STEVENSON, 2015, p.223).

Nota-se, aqui, o uso de palavras que denotam dúvida ("claridade incerta", "sombra tremulante"), reforçando o estado de incerteza e o estranhamento que pairam sobre o personagem, a se reforçar em muitas passagens do enredo, mesmo quando apenas para servir de contraste: "[...] na amplidão da casa, acima dele, ouvia com clareza uma movimentação de passos delicados, alguma presença" (STEVENSON, 2015, p.223).

Tanto a sombra quanto a presença sentida, na verdade, irão se revelar como a figura de si mesmo, a qual Markheim irá encontrar ao subir ao andar superior do prédio, que se achava vazio (a empregada estava fora no momento do crime, embora o protagonista soubesse que ela não tardaria a voltar, o que aumenta ainda mais a tensão da trama).

Antes disso, porém, existe uma intensificação do estado de paranoia, encaminhando o personagem para o encontro com 
o seu duplo, que representará também um encontro com a própria consciência culpada pelo cometimento de um crime por motivo torpe (dinheiro):

Em diversos espelhos luxuosos, alguns de fabricação local, outros procedentes de Veneza ou Amsterdã, [Markheim] viu seu rosto repetido muitas e muitas vezes, como se os reflexos fossem um exército de espiões; seus próprios olhos encontravam e detectavam sua presença; o som dos próprios passos, por mais leves que fossem, perturbavam a quietude do ambiente. [...] Temores irracionais ocupavam as áreas mais recônditas de seu cérebro num grande tumulto, como numa correria de ratos num sótão vazio: a mão do policial cairia pesada sobre seu ombro, e seus nervos se contrairiam como um peixe que tivesse sido fisgado; ou então ele contemplava, num desfile galopante, o banco dos réus, a prisão, a forca e o caixão preto (STEVENSON, 2015, p.221-222)

De acordo com Arrigucci Júnior (2015), os elementos até aqui referidos contribuem para aproximar a narrativa de Stevenson do conto fantástico e do relato de horror. Para Júlio França (2008), a "Literatura de horror" é uma designação comumente aplicada a textos ficcionais relacionados, de alguma maneira, ao sentimento de medo físico ou psicológico. E, quanto ao conto de Stevenson, em poucas passagens da trama fica mais evidente o esforço do autor em construir esse medo como no trecho a seguir:

Markheim temia que as leis da natureza, em seus empedernidos e imutáveis procedimentos, pudessem preservar alguma evidência que o condenasse pelo crime. Temia dez vezes mais, 
com um terror abjeto e supersticioso, alguma cisão na continuidade na experiência humana, alguma transgressão intencional da natureza (STEVENSON, 2015, p.227)

Esse receio da ruptura das leis naturais, causando-nos a dúvida sobre a própria sanidade mental do protagonista, que aparece aproximar-se da fronteira entre a loucura e a lucidez, é reforçada pela ideia de que a solidez dos elementos - as próprias paredes da loja de antiguidades onde o crime fora cometido - se desfizessem com o intuito de denunciá-lo, podendo "tornar-se transparentes e revelar seus movimentos como o das abelhas em colmeias de vidro" (STEVENSON, 2015, p.228).

Apesar de não sentir remorso pelo ato cometido e não estar certo da justiça dos homens, é, entretanto, o medo e a certeza da justiça divina que reforçam a tensão no protagonista, que se vê levado a uma angústia extrema. Ante a mistura desses sentimentos fortes, o medo se destaca, quase como pudesse se transmutar em um elemento físico, inquietando o leitor.

A propósito, de acordo com Lovecraft (1987), "a emoção mais forte e mais antiga do homem é o medo, e a espécie mais forte e mais antiga de medo é o medo do desconhecido" (1987, p.07). Para o teórico, ademais, a autenticidade de uma obra ligada ao horror não diz respeito ao enredo em si, mas exatamente à sensação que ela é capaz de produzir no leitor, e mesmo nos indivíduos mais racionais existiria uma espécie de herança biológica passível de ser tocada pelas narrativas que inspiram medo.

Roas (2014), por sua vez, evita usar o termo "medo", preferindo o vocábulo alemão Unheimlich (algo como "estranho", 
em tradução livre), admitindo, entretanto, que este seria um efeito que toda narrativa do gênero fantástico busca, de modo geral, produzir no leitor.

Ainda em Markheim, ao alcançar o andar superior da loja, para onde se dirige a fim de roubar a casa do antiquário assassinado e fugir de uma atmosfera denunciadora causada por sons, objetos e uma sombra que parece segui-lo, o protagonista depara-se imediatamente com uma série de tremós com muitos espelhos nos quais consegue se observar de diversos ângulos, "como um ator no palco" (STEVENSON, 2015, p.228).

Antes de lançar-se à caça aos tesouros escondidos, entretanto, ele é surpreendido por batidas à porta, acreditando tratar-se de oficiais da justiça humana. Porém, "o contorno do recém-chegado parecia modificar-se e ondular-se como o dos ídolos da loja iluminada pela luz trêmula da vela; por alguns momentos achou que o conhecesse; em outras, [...] que se parecia consigo mesmo" (STEVENSON, 2015, p.230). Neste ponto, o leitor vê escancararemse as portas do fantástico, e, novamente, fica visível o choque de que fala Todorov; o choque entre mundo natural e sobrenatural desvela-se mais uma vez, de modo decidido, aos olhos do leitor, e, também, para o personagem: "durante todo o tempo lá estava em seu peito, com uma sensação de terror quase palpável, a convicção de que aquela coisa não era da Terra nem de Deus" (STEVENSON, 2015, p.230).

Seria a própria figura do diabo? ("O senhor é o quê?... O demônio?" - STEVENSON, 2015, p.230). Ou uma aparição causada pela mente alucinada e perseguida de Markheim? O certo é que 
estamos diante de mais uma das constantes da literatura fantástica, na opinião de Todorov: "A existência de seres sobrenaturais, mais poderosos que os homens" (1992, p.118), bem como diante da ruptura entre matéria e espírito, que esse teórico também aponta como considerada, sobretudo no século XIX, como a primeira característica da loucura:

A multiplicação da personalidade, tomada ao pé da letra, é uma consequência imediata da passagem possível entre matéria e espírito: somos muitas pessoas mentalmente, em que nos transformamos fisicamente. Uma outra consequência do mesmo princípio tem mais extensão ainda: é o apagamento do limite entre sujeito e objeto. O esquema racional nos representa o ser humano como um sujeito que entra em relação com outras pessoas ou com coisas que lhe são exteriores, e que têm o estatuto de objeto. A literatura fantástica abala esta separação abrupta (1992, p.124-125)

De todo modo, é nesse ponto que leitor e protagonista parecem estar face a face com uma representação igualmente poderosa do mal, como se Markheim estivesse enxergando o mal em si mesmo em um elemento exterior, e que foge a seu controle. Essa impressão vai ser confirmada a partir da curiosa proposta com a qual o protagonista será tentado: a estranha e fluídica forma, alertando-o de que a empregada do antiquário não irá demorar a voltar para casa e flagrá-lo com as mãos sujas de sangue, oferece-lhe o favor de dizer-lhe onde está guardado o dinheiro do antiquário. ("O mal, para o qual eu vivo, não consiste em ação, mas em personalidade... e não é porque o senhor matou um antiquário, mas porque o senhor é Markheim, que me ofereço a ajudálo em sua fuga" - STEVENSON, 2015, p.234). 
O preço dessa oferta, entretanto - prontificar-se ao contínuo serviço do mal, mantendo-se mau -, parece caro demais a Markheim, nesse acerto de contas com a figura que representa sua própria consciência: ao mesmo tempo em que tenta justificar o cometimento do crime por conta de sua pobreza material, ele acredita ter o igual poder de colocar-se a serviço do bem, mesmo que seja de novo tentado por necessidades econômicas, o que o leva a afirmar que o outro não verá, portanto, selado seu pacto, isto é, a aceitação do mal em si mesmo, sobre todas as coisas.

Sem ceder, o estranho visitante continua a prevenir-lhe de que, como em todos os outros momentos da vida, Markheim voltará a sucumbir e a praticar o mal, permanecendo o mesmo. Entretanto, o protagonista, que reflete sobre sua capacidade de também poder praticar o bem, dá a resposta decisiva ao ouvir soar a campainha após uma breve trégua de silêncio, com a chegada da empregada à casa do antiquário: "É melhor a senhorita chamar a polícia... Eu matei o seu patrão" (STEVENSON, 2015, p.238).

E ante tal desfecho nos deparamos, ainda, com a ideia reveladora de ser o fantástico o terreno ideal onde podem ser exploradas na literatura, com o máximo proveito, variadas reflexões sobre a existência humana: a despeito da liberdade criadora proporcionada pelos domínios da ficção, todos os elementos do texto são organizados seguindo uma coerência interna própria (desde a escolha dos vocábulos), de modo a causar no leitor um estranhamento, que, a propósito, também contribuirá para fazê-lo refletir de modo mais profundo sobre a realidade que o cerca. 
A escolha do duplo como tema, por sua vez, reforça a necessidade de se olhar para a realidade como um terreno onde nada diz respeito a algo imutável e definido, mas múltiplo; essa multiplicidade, a propósito, persiste apesar das definições dos papéis sociais que um indivíduo possa desempenhar aos olhos dos outros - ou na ideia que tenha sobre si mesmo, como fica aparente no jogo de espelhos entre matéria e espírito explicitado em Markheim. - Conseguir enxergar bem essa multiplicidade em si mesmo pode significar, afinal, o alcance de uma compreensão melhor sobre os outros seres humanos, abrindo espaço para uma comunicação mais efetiva entre as pessoas e, sobretudo, um convívio social mais tolerante.

\section{REFERÊNCIAS}

ARRIGUCCI JÚNIOR, Davi (2015). “A poesia da circunstância”. In: STEVENSON, Robert Louis. O clube do suicídio e outras histórias. São Paulo: Cosac Naify, p.319-357.

FALCIONI, Davide (2005). "Desconstruindo Veneza”. In: NAZARIO, Luiz (Org.). A cidade imaginária. São Paulo: Perspectiva, p.123-148.

FRANÇA, Júlio (2008). "O horror na ficção literária: reflexão sobre o "horrível" como uma categoria estética". In: Anais do XI Congresso Internacional da ABRALIC: Tessituras, Interações, Convergências. São Paulo: USP.

FURET, François (1999). O homem romântico. Lisboa: Editorial Presença.

LOVECRAFT, H. P. (1987). "Introdução". In: . O horror sobrenatural em literatura. Rio de Janeiro: Ed. Francisco Alves, p.7-12.

NABOKOV, Vladimir. (2015). "Apêndice". In: STEVENSON, Robert Louis. O clube do suicídio e outras histórias. São Paulo: Cosac Naify, p.391-431.

POE, Edgar Allan (1975). Histórias extraordinárias. São Paulo: Círculo do Livro. (1981). "O homem das multidões". In: . Edgar Allan Poe: ficção completa, poesia \& ensaios. MENDES, Oscar (Trad.). Rio de Janeiro: Nova Aguilar, p.392-400. 
(1981). "O coração denunciador". In: Edgar Allan Poe: ficção completa, poesia \& ensaios. MENDES, Oscar (Trad.). Rio de Janeiro: Nova Aguilar, p.287-292.

ROAS, David (2014). A ameaça do fantástico: aproximações teóricas. São Paulo: Editora Unesp.

STEVENSON, Robert Louis (2015). "O clube do suicídio". In: O clube do suicídio e outras histórias. São Paulo: Cosac Naify, p.7-108. (2015). Markheim. In: . O clube do suicídio e outras histórias. São Paulo: Cosac Naify, p.213-238. (2015). O estranho caso de Dr. Jekyll e Mr. Hyde. In: O clube do suicídio e outras histórias. São Paulo: Cosac Naify, p.109-211. TODOROV, Tzvetan (1992). Introdução à literatura fantástica. São Paulo: Perspectiva. 